\title{
The Hoarding Phenomenon in Schizophrenia Spectrum Disorders
}

\author{
Marie Lundholm Schou ${ }^{a, b}$ Annick Urfer-Parnas ${ }^{b}$ Josef Parnas ${ }^{a, c, d}$

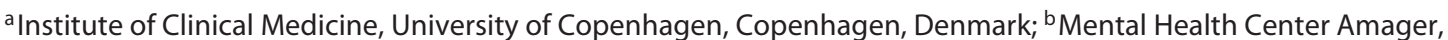 \\ University Hospital of Copenhagen, Copenhagen, Denmark; ${ }^{C}$ Mental Health Center Glostrup, University Hospital \\ of Copenhagen, Broendby, Denmark; ${ }^{d}$ Center for Subjectivity Research, University of Copenhagen, Copenhagen, \\ Denmark
}

\section{Keywords}

Hoarding · Schizophrenia · Self-disorders · Diagnosis · Insight · Classification

\begin{abstract}
The presence of hoarding behavior among patients with schizophrenia has been known for more than a century. Nevertheless, only a few studies have examined the hoarding phenomenon among patients with schizophrenia, and no studies have examined the potential motivation. Hoarding disorder became a separate diagnosis in DSM-5. Studies about hoarding disorder use primarily quantitative approaches (e.g., scales, self-administered questionnaires, and structured interviews) when assessing the patients. The main objectives of this study were to examine the meaning of hoarding for patients with schizophrenia spectrum disorders and to explore associated psychopathology which may motivate the hoarding. We have examined 13 patients diagnosed with schizophrenia spectrum disorders showing hoarding behavior. The patients underwent semistructured, narrative interviews about the following domains: the time of onset of hoarding, the meaning of hoarding and associated psychopathology, the presence of insight into hoarding, and problematic issues about discarding. The study shows that hoarding begins very early in life for these pa-
\end{abstract}

tients and can be motivated by various psychopathologies. Diminished sense of basic self and transitivistic experiences were mentioned by several patients as motivations for collecting objects. Furthermore, the difficulty with discarding reflected a huge ambivalence and ruminations. Our findings suggest that thorough and comprehensive assessments of people with hoarding symptoms are necessary to assure the correct diagnosis and to understand the patient. An increased knowledge of the patients' motivations for hoarding behavior may also be useful for the treating personnel and may prevent social adversities. We think it is questionable that in the DSM-5 hoarding is not mentioned in the description of schizophrenia but has been elevated to a separate disorder.

(c) 2020 The Author(s)
Published by S. Karger AG, Basel

\section{Introduction}

The presence of the hoarding habit among patients with schizophrenia is mentioned as early as in Bleuler's [1] description of the illness from the beginning of the 20 th century. He described hoarding as a symptom in advanced schizophrenia where patients collect useful as well as useless objects and store these objects in their homes so they can hardly move around. The American psychia-

\begin{tabular}{ll}
\hline $\begin{array}{l}\text { karger@karger.com } \\
\text { www.karger.com/psp }\end{array}$ & $\begin{array}{l}\text { (c) 2020 The Author(s) } \\
\text { Published by S. Karger AG, Basel }\end{array}$ \\
Karger & $\begin{array}{l}\text { This is an Open Access article licensed under the Creative Commons } \\
\text { Attribution-NonCommercial-4.0 International License (CC BY-NC) } \\
\text { (http://www.karger.com/Services/OpenAccessLicense), applicable to } \\
\text { the online version of the article only. Usage and distribution for com- } \\
\text { mercial purposes requires written permission. }\end{array}$
\end{tabular}

Marie Lundholm Schou

Mental Health Center Amager

University Hospital of Copenhagen

Digevej 110, DK-2300 Copenhagen (Denmark)

marielundholm@gmail.com 
trist Silvano Arieti [2] was very interested in hoarding as a symptom of schizophrenia. He defined hoarding as "the practice of collecting a more or less large number of objects, generally of limited size and of no practical use." Arieti [2] described hoarding as a symptom of the "preterminal" stage of the illness where delusions and hallucinations often have disappeared. Hoarding has also been considered a mannerism and thereby a common symptom among patients with catatonic schizophrenia [3]. In agreement with Bleuler's and Arieti's findings, commonly collected items among these patients were found to be rubbish, newspapers, and food. The patients often resist to discard the rubbish but no studies have examined the motivation behind that resistance. In DSM-3 (published in 1980) "collecting of garbage" and "hoarding of food" are mentioned as examples for markedly peculiar behavior as possible prodromal or residual symptoms of schizophrenia [4].

Specific research about hoarding started in the 1990s. Hoarding has since been defined as "the acquisition of and failure to discard possessions that appear to be useless or of limited value" [5].

In DSM-5, hoarding is not mentioned as a symptom of schizophrenia but has been instead elevated to an independent diagnostic category of hoarding disorder. Presumably, hoarding disorder will be incorporated in ICD11 as well [6].

Several scales for diagnosing hoarding disorder have been developed mainly to quantify the severity of hoarding, to examine whether the challenging issue for the patient is excessive acquisition or difficulties with discarding, and if the patient is restricted by the hoarding [7-10]. Very few studies have examined motives for collecting objects and only through self-questionnaires or rating scales [11-13]. These motives have been categorized into 4 different areas: fear of losing information, emotional reasons, waste avoidance, and aesthetic reasons [12]. Such approach is mainly focused on third-person description and neglect qualitative and subjective aspects of the phenomenon.

Only a few studies have investigated the presence of hoarding in patients diagnosed with schizophrenia. One study investigated the hoarding habit in 100 hospitalized patients with dementia [14]. Five patients showed clinically significant symptoms of hoarding. Four of these patients were diagnosed with paranoid schizophrenia. None of the patients explained hoarding in terms of a particular delusion, but they were not specifically interviewed about the aim of their hoarding. A Chinese study examined 30 patients with hoarding behavior and found that about half of the patients suffered from schizophrenia [15]. The patients were interviewed in a semistructured manner, for example, about the meaning of the hoarding. More than $80 \%$ of the participants argued that they hoarded for material gain whereas about $25 \%$ claimed that psychological or emotional gain was most important. The majority of the participants failed to elaborate their motives more precisely. Novara et al. [16] found that $5.9 \%$ of patients with psychotic disorders showed signs of hoarding measured using the Saving Inventory Revised (SI-R) questionnaire.

Overall, the lack of empirical-phenomenological studies of hoarding is striking both among patients diagnosed with hoarding disorder and patients with other psychiatric disorders associated with hoarding symptoms. To our knowledge, no study has described associated psychopathology which may motivate hoarding behavior with a phenomenological approach. We decided to do an empirical-phenomenological study of a group of patients diagnosed with schizophrenia spectrum disorders and displaying hoarding behavior. The aims of the study were to examine the following areas of hoarding:

1. The time of onset.

2. The meaning and associated psychopathology.

3. The presence of insight.

4. Problematic issues about discarding.

\section{Methods}

The present study was designed as a qualitative study.

Recruitment. Patients were recruited from outpatient units in 2 out of the 5 psychiatric centers in the capital region of Denmark. The interviewer personally contacted outpatient clinics and through contact with case managers and psychiatrists inquired about the potential study subjects. We searched for patients diagnosed with schizophrenia spectrum disorders showing signs of hoarding (having a large amount of possessions).

Diagnosis. ICD-10 diagnoses were established through clinical interview performed by senior psychiatric consultants involved in the treatment of the patients. Subsequently, the authors have reviewed the participants' psychiatric records to confirm the diagnosis.

Sample. Due to the qualitative and time-consuming nature of the study, 13 patients were interviewed. Four patients refused to participate in the study. The patients had to be able to tolerate a lengthy interview because the goal of the study was to uncover the qualitative aspects of hoarding or collecting. Patients with clinical dominating alcohol or drug abuse or brain disorder were excluded from the study.

Interview. An interview template was developed based on a review of existing literature [12,17-20], discussions within the research group based on clinical case descriptions, and pilot interviews. We wanted to investigate the 4 domains corresponding to 
Table 1. EASE items included in the interview template

Cognition and stream of consciousness (EASE domain 1)

Thought pressure (1.3)

Ruminations-obsessions (1.6)

Ambivalence (1.9)

Self-awareness and presence (EASE domain 2)

Diminished sense of basic self (2.2)

Hyperreflectivity (2.6)

Loss of common sense (2.12)

Anxiety (2.13)

Demarcation/transitivism (EASE domain 4)

Other transitivistic phenomena (4.5)

Existential reorientation (EASE domain 5)

As if feelings of extraordinary creative power, insight into hidden dimensions of reality, or insight into own mind or the mind of others (5.4)

the aims of the study listed in the introduction. The interview included several a priori selected items from the Examination of Anomalous Self-Experience Scale (EASE scale) listed in Table 1 [21]. The interviews were semistructured, and the patients were encouraged to provide further detailed descriptions of their experiences according to standard phenomenological principles [22]. For the majority of the patients, the interview was divided into 2 shorter interviews. In total, each patient was interviewed for 1-3 h. The patients were interviewed at a place of their choice (at home, at their outpatient clinic, or at the interviewer's office). Home visits were performed for 9 of the patients; 11 out of 13 patients accepted audio recording of the interview allowing verbatim transcription, which enabled more detailed evaluation and analysis. For the patients not recorded, analysis was performed based on comprehensive written notes taken during the interview. The transcripts were read by all authors in order to achieve a consensus evaluation. The interviewer (M.L.S.) had been trained in psychiatry for 1 year at the time of the interviews. The initial interviews were supervised by one of the co-authors (A.U.-P.), who is a senior psychiatric consultant experienced in phenomenological psychopathology.

Analysis. The analysis was based on phenomenological considerations following the principles of thematic analysis [23] and ongoing interaction between theoretical knowledge and empirical observations attempting to identify associated psychopathology which may motivate the hoarding.

\section{Results}

The sociodemographic data are shown in Table 2.

\section{Onset of Hoarding/Collecting}

The median age at the onset of hoarding was 11 years (range 7-44 years) and typically preceded the age at first contact with the psychiatric facility (median 25 years, range $7-56$ years).
Table 2. Descriptive characteristics

$\begin{array}{lc}\text { Gender, females/males } & 4 / 9 \\ \text { Median age (range), years } & 55(27-75) \\ \text { Unmarried, \% } & 100 \\ \text { Diagnosis, \% } & \\ \quad \text { Paranoid schizophrenia } & 77 \\ \quad \text { Undifferentiated schizophrenia } & 8 \\ \quad \text { Schizotypal personality disorder } & 15 \\ \text { Educational level, \% } & \\ \quad \text { Primary school or less } & 23 \\ \quad \text { High school } & 31 \\ \quad \text { Finished vocational education } & 15 \\ \quad \text { Started university } & 15 \\ \quad \text { Finished university } & 15 \\ \text { Employment, \% } & \\ \quad \text { Disability pension } & 85 \\ \quad \text { Sick leave } & 7 \\ \text { Ongoing education } & 7\end{array}$

Table 3. Descriptive characteristics of the patients' psychiatric disorders

\begin{tabular}{|c|c|}
\hline Patient & Collected items \\
\hline 1 & Useful things to his homebuilt "machine" \\
\hline 2 & Broad range of things, especially clothes \\
\hline 3 & $\begin{array}{l}\text { Empty cardboard boxes, electronic devices, physical } \\
\text { memories }\end{array}$ \\
\hline 4 & $\begin{array}{l}\text { Broad range of things, for example, indoor decorations, } \\
\text { objects from the 50s, plastic bags, newspapers }\end{array}$ \\
\hline 5 & Electronic devices \\
\hline 6 & Toy figures \\
\hline 7 & $\begin{array}{l}\text { Broad range of things, for example, clothes, shoes, } \\
\text { newspapers, food }\end{array}$ \\
\hline 8 & Letters, sport match tickets \\
\hline 9 & Food, clothes, craft items \\
\hline 10 & $\begin{array}{l}\text { Broad range of things, for example, books, } \\
\text { advertisement, magazines, kitchen equipment }\end{array}$ \\
\hline 11 & Movies and CDs, electronic devices, clothes \\
\hline 12 & $\begin{array}{l}\text { Broad range of things, for example, religious figures, } \\
\text { flowers, teddies, art }\end{array}$ \\
\hline 13 & Books, records, bottles, cigarette boxes \\
\hline
\end{tabular}

For the majority of patients, the hoarding started as an interest for a given object, and gradually their collection grew to an enormous number of things, and, therefore, the term "collecting" is used throughout this section. 
Table 3 shows the collected items. We did not find an obvious pattern in collected items.

Only few patients were able to describe the debut in detail:

- I didn't know how to spend my time. It gave me a kick to visit flea markets, and I got to socialize. It became a mania, a manner to get some meaning in my life, even though it was like peeing in my pants. And then it went out of control.

- I remember I saved my stickers on the sheet and I didn't use my favourite pencils. I never used them because if I did, I couldn't get this specific sticker or pencil again. It was kind of irreversible, and I didn't like it.

\section{Meaning of Hoarding and Associated Psychopathology}

For the majority of the patients, their possessions had a very prominent role, and their belongings were fundamentally important to maintain their meaning in life:

- The hoarding gave me an inner silence, a calm in my body. It was a kind of consolation for my other obsessions. I think it is relaxing to look at boxes. It is stimulating. I don't look at them every day or have them in my hand. They are just in the corner. I feel comfortable with them standing there.

- I feel rich when I have my belongings. They give me love. They are my girlfriends, my father, mother, my children. It is like being married and having children. Of course, on another level, in another world. It is like we live together, and we have rules as in a collective housing.

- I think it is partly because I don't remember life events as others. I'm not that organized. When my friends talk about their past, they tell specific stories. I'm more everywhere, and I can't pick one specific thing. I don't know what I know until something external triggers me. I remember my memories from physical things.

- I have talked about the feeling of lacking my inner core. I adapt easily to the environment and things around me. So, it makes sense that my belongings have made me to who I am. My things keep me on the track to an idea.

- Because of my belongings, I have a history. But I never use them, they are just there. Otherwise I would become empty inside.

- Do you use all your clothes? No, I don't. I simply have too much. I save some of it because I think I can redesign it, or change some details. Sometimes I buy a piece of cloth because it is so beautiful, a dress in such a beautiful fabric, and I think I'll change this and this, and then it would fit me. But I never come around doing it.

Three patients described deep physical discomfort when others touch their belongings.

- I don't like it when people touch my things. They are very personal. It brings disorder to the energies. I don't touch them either, and I try not to look at them too much. Then the energies vibrate wrongly.

- I don't like when people touch my things. It's like a piece of me falling apart, like something breaking inside me. This feeling disappears over time. But it is very difficult. I feel such a discomfort in my body.
About half of the patients described disturbances in self-experience. We exemplify these disturbances in a detailed case vignette from our sample:

- Olivia has collected things as long as she remembers. She is afraid of being destroyed if she does not have her possessions. She explains that she would be vulnerable and break into small pieces without them. Her things protect her against destruction. It would be an irretrievable loss for her if she lost all her belongings, and it would not be the same if her possessions were replaced by new things. The absence of her things would create a psychical emptiness around her. She needs the things to keep herself together. They create the effect of a box and prevent her from flying away from her body. She has once slept in a friend's apartment, which was emptier than her own. When she woke up, she felt her body's barriers began to disappear and that she started dissolving into the surroundings. She felt that the absence of things surrounding her was responsible for the feeling of dissolution. She doesn't like it when someone else touches her belongings or even looks too much at them. They cross her boundaries; they enter her court. She feels that by touching or observing her belongings, people can acquire a lot of details about her, which she does not give them voluntarily. Whenever she discards anything, she always considers it for several weeks beforehand. Afterwards, her mind is occupied with repeating thoughts about whether or not she should have discarded the item. When discarding, she becomes overwhelmed by a profound anxiety which is distinguishable from other more specific forms of anxiety such as social anxiety. It feels like being run over by a truck. Olivia's belongings help masking this deep anxiety, and thereby they become a fixed point in her life.

\section{Presence of Insight into Hoarding}

None of the patients defined their hoarding as an illness. One patient considered his uncontrolled acquisition as an illness while he found that storing of the objects and difficulties with discarding were normal. The majority of participants considered the hoarding a part of their identity; they simply did not mean they hoarded more than anyone else.

- I haven't really thought about it. I have just accepted it. For me, it makes sense. I think, if you're feeling bad, you lose the meaning with everything. Collecting gives meaning to your life, something you can relate to.

- I don't think the hoarding is a part of my schizophrenia. But I think they overlap and influence one another. It just happens, it is out of my control. The hoarding is still fluffy to me. I think it is a kind of strategy to cope with an imbalance in myself.

- I don't think it is a part of my schizophrenia. Or it could be. I have been schizophrenic for more than 30 years. I can't really distinguish between what is sickness and what is not. It is one unity. It is not out of fun that I've bought all these things. I had something I needed to collect, I had something I had to live through. 


\section{Problematic Issues about Discarding}

All the patients except 2 mentioned discomfort when throwing things out. Generally, the patients were influenced by a vast ambivalence and ruminations about the possibility of needing the things in the future.

- I have a deal with my case manager that every time she visits me, I have to find at least one thing to discard. Sometimes I decide to throw out a single rubber band. But still, I don't like doing it.

- It is relieving when I've discarded something. But still I feel like I miss something. But it is not like really missing, more that it just took up space. It is relieving but, at the same time, it is anxiety triggering. But it is because I need to choose. I have to choose whether or not I want to save it. That is anxiety triggering. As long as I remember, it has been like that with me and my possessions. Valuable things, and how I can choose whether or not a thing should be thrown out. If I had a little box where I could save everything, with eternal room, then I would do it, to some extent.

- But how to do it? I know how I do it technically. But how do I do it? My case manager says I need to practice and practice. But do I ever manage to get it done? And when I'm not here anymore?

Several of the patients have experienced someone else has discarded some of their belongings, or they had sold some of their possessions.

- A friend of mine cleaned my rest room, and she had thrown out my toilet brush without asking me. I liked that toilet brush. So, I retrieved it from the building's trash can. It wasn't cool. Then other people would think I'm weird when I rummage in the trash.

- Once a friend of mine had bought some of my records. It was very difficult for me to handle. So, I had to tell him I wanted the records back, and he got his money back. It was just a feeling, a discomfort. Some stupid records, and I actually never listened to them. But I didn't like selling them.

The patients were asked what would happen if they need to throw everything out. The majority thought it would be horrible, whereas a minority of the patients thought it would be relieving if they disposed of their possessions.

- I can't discard my possessions. It would make a hole in my redemption. I would lose my entire life. Like puncturing a balloon. What I of course wouldn't lose.

- I think it would be relieving. Apparently, I will always have too many things. But I think it would be relieving if I could clean and use my apartment. But I doubt it will ever happen.

\section{Discussion}

This is the first study investigating the hoarding phenomenon from a phenomenological perspective. A limitation of the study is the small sample size $(n=13)$, neces- sitated by the time-consuming nature of the study. All the participants suffered from schizophrenia spectrum disorders. Thus, while this study must be considered a pilot study, and the data cannot be generalized, it provides useful information about reasons for hoarding in schizophrenia.

This study shows that hoarding among patients suffering from schizophrenia is associated with different constellations of psychopathology. Moreover, the majority of patients began to collect many years before they started treatment in the psychiatric system and before experiencing psychotic symptoms. None of the patients sought help because of their hoarding but for other reasons. Anomalous self-experiences have been shown specifically among patients with schizophrenia [24], and they are present long before the patients are diagnosed with their primary illness [25-28]. This is a possible explanation for the early onset of hoarding. Some patients described a lack of their inner core and that their belongings supported them in feeling present in the common, material world, and in keeping with the continuity of their existence in time. Hoarding may be envisaged as a kind of compensation for fundamental disturbances of subjectivity.

Many patients described transitivistic and influence phenomena in relation to their belongings. These may be considered a continuum where influence phenomena are the ultimate psychotic experience of transitivism. One study of self-perceived hoarders outside the public psychiatric system has described similar transitivistic-like statements like, for example, possessions viewed as an extension of themselves and of feeling violated when other people touch their belongings [13]. However, this study did not elaborate on the quality of experience or another psychopathology, and those experiences were classified merely as "emotional reasons" for hoarding.

Discarding was a matter of concern for all the patients. They were convinced that they would need the possessions in the future. However, the majority of patients did not currently use their possessions and had no intentions to start using them in the near future. Other things were stored because of memories, and, thereby, the patients felt attached to them. The patients' perception of time seemed to manifest a sort of eternity without dynamism [29]. Altogether, the perceived distress when discarding reflected hyperreflectivity and problems with common sense [30,31].

When the patients for one reason or another were forced to throw something out, they were affected by a huge ambivalence and contemplated discarding for several weeks. 
None of the patients considered hoarding to be an illness. Instead, they regarded hoarding as a part of their identity and a fixed point of their existence.

Until the 1990s, hoarding was considered as a symptom rather than a separate disorder. Since hoarding was mentioned as a prodromal or residual symptom of schizophrenia and not in other diagnostic criteria in DSM-3, it must be presumed that the inclusion of hoarding in the psychopathology of schizophrenia was continuous with the original description of schizophrenia and with clinical experience. Our results support the formulation of DSM-3. Until the 1990s, diagnostic assessments of psychiatric disorders were based on comprehensive clinical interviews including second informant information [32]. The general shift towards a more streamlined and simplified diagnostic assessment based on structured questionnaires and scales has probably contributed to hoarding often being overlooked as a symptom of a more comprehensive picture of schizophrenia spectrum psychopathology today. This has probably contributed to considering hoarding as an isolated phenomenon and to a more general tendency to increasing atomization of syndromic entities into multiple distinct disorders (a so-called "comorbidity") [33]. Our findings suggest that a thorough assessment based on clinical interviews of patients showing symptoms of hoarding is necessary to detect associated psychopathology which is diagnostically relevant.

In order to fulfil the DSM-5 criteria for hoarding disorder, the hoarding behavior must not be explainable by "delusions in schizophrenia or another psychotic disorder," but the exclusion criterion does not mention other symptoms of schizophrenia as possible causes for the hoarding habit. Only 3 of the participants in this study explained hoarding in terms of delusions while the remaining patients explained hoarding by more fundamental and basic symptoms characteristic for schizophrenia. If the forthcoming ICD-11 retains the hierarchal structure it would be advisable that the definition of the hoarding disorder contains the exclusion criterion with a reference not only to flamboyant psychotic symptoms but also to disorders of subjectivity.

\section{Conclusion}

Using a qualitative approach, we studied associated psychopathology of hoarding in a group of patients diagnosed with schizophrenia spectrum disorders. The study shows that hoarding begins very early in life and can be motivated by a variety of psychopathological phenomena that appear meaningful in this particular context. The exact motivation for hoarding cannot be assessed through structured interviews or self-administered questionnaires. Our findings indicate that hoarding can be associated with different subjectivity disturbances. Although a comprehensive psychopathological assessment is not always incorporated as a standard in daily routine, we are convinced that more thorough assessment would expose relevant psychopathology. An intimate knowledge of the patients' motivations for the hoarding behavior may also be useful for the treating personnel in negotiating with the patients' different possibilities of coping with the problem. That negotiation may prevent social adversities such as being evicted from one's apartment.

\section{Acknowledgments}

The authors thank all the participants and the clinical staff.

\section{Statement of Ethics}

Ethics approval was not required. Written informed consent was given by all participants.

\section{Disclosure Statement}

The authors have no conflicts of interest to declare.

\section{Funding Sources}

The authors have not received any funding.

\section{Author Contributions}

A.U.-P. and J.P. conceived the idea for the study; M.L.S. developed the interview template, which was verified by A.U.-P. and J.P.; M.L.S. conducted the interviews, initially supervised by A.U.-P.; all authors discussed the results; M.L.S. wrote the first manuscript, and all authors have closely read it and contributed to the final manuscript. 


\section{References}

1 Bleuler E. Dementia praecox or the group of schizophrenias. Zinkin J, Lewis NDC, translators. New York: International University Press; 1950.

2 Arieti S. Primitive habits in the preterminal stage of schizophrenia with particular reference to the hoarding and self-decorating habits. J Nerv Ment Dis. 1945;102(4):367-75.

3 Hamilton M. Fish's schizophrenia. 2nd ed. Bristol: Wright; 1976.

4 American Psychiatric Association. DSM-III diagnostic and statistical manual of mental disorders. 3rd ed. Washington (DC); 1980.

5 Frost RO, Hartl TL. A cognitive-behavioral model of compulsive hoarding. Behav Res Ther. 1996 Apr;34(4):341-50.

6 Fontenelle LF, Grant JE. Hoarding disorder: a new diagnostic category in ICD-11? Br J Psychiatry. 2014;36 Suppl 1:28-39.

7 Frost RO, Steketee G, Grisham J. Measurement of compulsive hoarding: saving inventory-revised. Behav Res Ther. 2004 Oct;42 (10):1163-82.

8 Frost RO, Hristova V, Steketee G, Tolin DF. Activities of daily living scale in hoarding disorder. J Obsessive Compuls Relat Disord. 2013 Apr;2(2):85-90.

9 Tolin DF, Frost RO, Steketee G. A brief interview for assessing compulsive hoarding: the Hoarding Rating Scale-Interview. Psychiatry Res. 2010 Jun;178(1):147-52.

10 Frost RO, Steketee G, Tolin DF, Renaud S Development and Validation of the Clutter Image Rating. J Psychopathol Behav Assess. 2008;30:193-203.

11 Frost RO, Gross RC. The hoarding of possessions. Behav Res Ther. 1993 May;31(4):36781.

12 Frost RO, Steketee G, Tolin DF, Sinopoli N, Ruby D. Motives for Acquiring and Saving in Hoarding Disorder, OCD, and Community Controls. J Obsessive Compuls Relat Disord. 2015 Jan;4:54-9.
13 Frost RO, Hartl TL, Christian R, Williams N. The value of possessions in compulsive hoarding: patterns of use and attachment. Behav Res Ther. 1995 Nov;33(8):897-902.

14 Stein DJ, Laszlo B, Marais E, Seedat S, Potocnik F. Hoarding symptoms in patients on a geriatric psychiatry inpatient unit. S Afr Med J. 1997 Sep;87(9):1138-40.

15 Chiu SN, Chong HC, Lau SP. Exploratory study of hoarding behaviour in Hong Kong. Hong Kong J Psychiatry. 2003;13:23-30.

16 Novara C, Bottesi G, Dorz S, Sanavio E. Hoarding symptoms are not exclusive to hoarders. Front Psychol. 2016 Nov;7:1742.

17 Corin E, Lauzon G. Positive withdrawal and the quest for meaning: the reconstruction of experience among schizophrenics. Psychiatry. 1992 Aug;55(3):266-78.

18 Thoma S. Inhabiting the Shared World: Phenomenological Considerations on Sensus Communis, Social Space and Schizophrenia. In: Hipólito I, Gonçalves J, Pereira J, editors. Schizophrenia and common sense: explaining the relation between madness and social values. Studies in brain and mind. Cham, Switzerland: Springer; 2018. Vol. 12, p. 19-37.

19 Minkowski E. Minkowski's structural approach. In: Broome M, Harland R, Owen G, Stringaris A, editors. The Maudsley Reader in Phenomenological Psychiatry. New York, NY: Cambridge University Press; 2012. p. 102-16.

20 Minkowski E. The essential disorder underlying schizophrenia and schizophrenic thought (1927). Translated by Cutting J. In: Broome M, Harland R, Owen G, Stringaris A, editors. The Maudsley Reader in Phenomenological Psychiatry. New York, NY: Cambridge University Press; 2012, p. 143-54.

21 Parnas J, Møller P, Kircher T, Thalbitzer J, Jansson L, Handest P, et al. EASE: examination of anomalous self-experience. Psychopathology. 2005 Sep-Oct;38(5):236-58.
22 Jansson L, Nordgaard J. The psychiatric interview for differential diagnosis. Springer International; 2016.

23 Braun V, Clarke V. Using thematic analysis in psychology. Qual Res Psychol. 2006;3(2):77101.

24 Nordgaard J, Parnas J. Self-disorders and the schizophrenia spectrum: a study of 100 first hospital admissions. Schizophr Bull. 2014 Nov;40(6):1300-7.

25 Parnas J, Carter J, Nordgaard J. Premorbid self-disorders and lifetime diagnosis in the schizophrenia spectrum: a prospective highrisk study. Early Interv Psychiatry. 2016 Feb 10(1):45-53.

26 Nelson B, Thompson A, Yung AR. Basic selfdisturbance predicts psychosis onset in the ultra high risk for psychosis "prodromal" population. Schizophr Bull. 2012 Nov;38(6):127787.

27 Raballo A, Parnas J. The silent side of the spectrum: schizotypy and the schizotaxic self. Schizophr Bull. 2011 Sep;37(5):1017-26.

28 Koren D, Tzivoni Y, Schalit L, Adres M, Reznik N, Apter A, et al. Basic self-disorders in adolescence predict schizophrenia spectrum disorders in young adulthood: A 7-year follow-up study among non-psychotic helpseeking adolescents. Schizophr Res. 2019, Epub ahead of print.

29 Minkowski E. Lived time. Evanston: Northwestern University Press; 1970.

30 Stanghellini G. Vulnerability to schizophrenia and lack of common sense. Schizophr Bull. 2000;26(4):775-87.

31 Parnas J, Bovet P. Autism in schizophrenia revisited. Compr Psychiatry. 1991 Jan-Feb; 32(1):7-21.

32 Tucker GJ. Putting DSM-IV in perspective. Am J Psychiatry. 1998 Feb;155(2):159-61.

33 Maj M. "Psychiatric comorbidity": an artefact of current diagnostic systems? Br J Psychiatry. 2005 Mar;186(3):182-4. 